\title{
Pobreza, discapacidad y derechos humanos ${ }^{1}$
}

\section{Poverty, disability and human rights}

\section{Resumen}

Se estima que el I $5 \%$ de la población mundial tiene una discapacidad.

Existe un vínculo directo entre pobreza y discapacidad. La población con discapacidad se encuentra entre la más desaventajada y discriminada. Sin embargo, las teorías económicas sobre desarrollo han omitido cuestiones esenciales sobre esta población, contribuyendo a su invisibilidad y pobreza. La teoría de las capacidades desde un enfoque basado en los derechos humanos nos proporciona una nueva dimensión del desarrollo. Los costes extraordinarios derivados de la discapacidad y de las barreras psicológicas, físicas y sociales a las que se enfrentan las personas con discapacidad contribuyen a su pobreza, falta de libertad y vulneración de derechos humanos, y así se evidencia en los diferentes estudios llevados a cabo. La cooperación para el desarrollo se convierte en una herramienta esencial para la promoción de los derechos de las personas con discapacidad y la lucha contra la pobreza.

\section{Palabras clave}

Discapacidad, costes extraordinarios, derechos humanos, pobreza, cooperación para el desarrollo.

\begin{abstract}
It is estimated that persons with disabilities represent $15 \%$ of the world population. There is a strong link between poverty and disability. Population with disabilities is among the most disadvantaged and discriminated. However, development economic theories have forgotten essential matters about this population, contributing towards their invisibility and poverty. The Capability Approach from a Human Rights based approach brings us a new dimension. The extraordinary costs that arise from a disability and from the psychological, physical and social barriers that persons with disabilities face, contribute to their poverty, lack of freedom and vulneration of human rights, as put forward by current studies on this subject. International co-operation becomes a very valuable tool to be used for the promotion of the rights of persons with disabilities and overcoming poverty.
\end{abstract}

\section{Keywords}

Disability, extraordinary costs, human rights, poverty, international co-operation.

I. Este artículo recoge una síntesis de dos estudios más amplios en la materia realizados por la autora (Martínez Ríos, 20II) y (Martínez Ríos, 20I2).

\author{
Beatriz Martínez Ríos \\ <bmartinezrios@yahoo.es> \\ Comité Español de Representantes \\ de Personas con Discapacidad y sus \\ Familias (CERMI)
}

Para citar:

Martínez Ríos, B. (20I3): "Pobreza, discapacidad y derechos humanos", Revista Española de Discapacidad, I (I): 9-32.

<http://dx.doi.org/IO.5569/234O5IO4.OI.OI.OI>

Fecha de recepción: 5-II-20I2 Fecha de aceptación: 22-4-20I3 


\section{Concepto de discapacidad}

El término 'discapacidad' presenta diversas interpretaciones dependiendo del paradigma desde el que se define y, debido a las diferencias de criterios, no hay acuerdo sobre su estimación, lo que hace que sea muy complicado comparar los datos estadísticos existentes y hablar con coherencia de la situación de las personas con discapacidad a escala internacional. En la mayoría de los casos, estas diferencias se deben a la cultura, los intereses, el nivel económico, la capacidad de detección y el nivel de desarrollo de las políticas sociales de cada país, así como a la metodología utilizada en la recopilación de los datos y el objeto para el que se emplea la definición (Bolderson et al., 2002; OMS, 20II). En muchas ocasiones, su conceptualización es demasiado restrictiva y las estimaciones se efectúan a la baja. Esta situación se produce, entre otras cosas, porque cuanto mayor es el número de personas con discapacidad reconocida, también lo es el número de prestaciones sociales necesarias, y en consecuencia, la cuantía de recursos que deben estar disponibles para proporcionarlas.

Un primer paso para entender el fenómeno de la discapacidad es explorar lo que ésta significa para aquellas personas que la tienen. Lo que las personas con discapacidad manifiestan es que lo que más les cuesta no es entender, aceptar o sobrellevar su deficiencia, sino vivir con la hostilidad, los prejuicios y la discriminación a la que se enfrentan todos los días simplemente por el hecho de tener una discapacidad (Coleridge, 2006).

Con la entrada en vigor de la Convención de Naciones Unidas sobre los Derechos de las Personas con Discapacidad en mayo de 2008 , se ha creado un marco jurídico de carácter vinculante para los países ratificantes y una herramienta de referencia fundamental para la conceptualización de la discapacidad y la formulación de políticas a escala internacional. La Convención define a las personas con discapacidad, en su artículo I, como:
Aquellas que tienen deficiencias físicas, mentales, intelectuales o sensoriales a largo plazo que, al interactuar con diversas barreras, puedan impedir su participación plena y efectiva en la sociedad, en igualdad de condiciones con las demás (ONU, 2006a: 4).

La definición utilizada en la Convención se basa en un modelo social en el que el respeto a los derechos humanos de las personas con discapacidad es esencial. Se ha pasado de definir la discapacidad en el marco de un modelo caracterizado por una relación agente/paciente, a tratarla dentro de otros modelos en los que se considera que la libertad humana, económica, política y social conducen al desarrollo, por lo que es indispensable que las personas con discapacidad alcancen estas libertades y derechos para que realmente éste se produzca. Ver a la persona con discapacidad como un sujeto en lugar de como un objeto supone darle acceso al beneficio pleno de las libertades fundamentales que la mayoría de las personas dan por sentadas, y hacerlo de forma respetuosa y sensible a su diferencia. Todo ello implica abandonar la tendencia a percibir a la persona con discapacidad como un problema, para verla, en cambio, en el contexto de sus derechos (Quinn et al., 2002).

Tal y como muestra la Figura I, la discapacidad tiene dos componentes esenciales, cuya interacción da lugar a situaciones diferentes. Estos son: la propia persona y el contexto social en el que se desenvuelve.

La deficiencia que una persona tiene puede ser mucho más limitante en una sociedad que en otra; depende de los obstáculos con los que la persona se encuentre y su grado de inclusión en la sociedad. También es fundamental para determinar su situación real la actitud social hacia la persona con discapacidad, a fin de proporcionar por derecho la habilitación necesaria que le permita alcanzar la igualdad de oportunidades. Una persona con discapacidad que cuenta con asistencia, apoyos o adaptaciones técnicas necesarias para su funcionamiento está habilitada para desarrollar sus capacidades con todo su potencial, y en este sentido, se encontrará en igualdad de 
Figura 1. Interacción de los componentes que dan lugar a la discapacidad

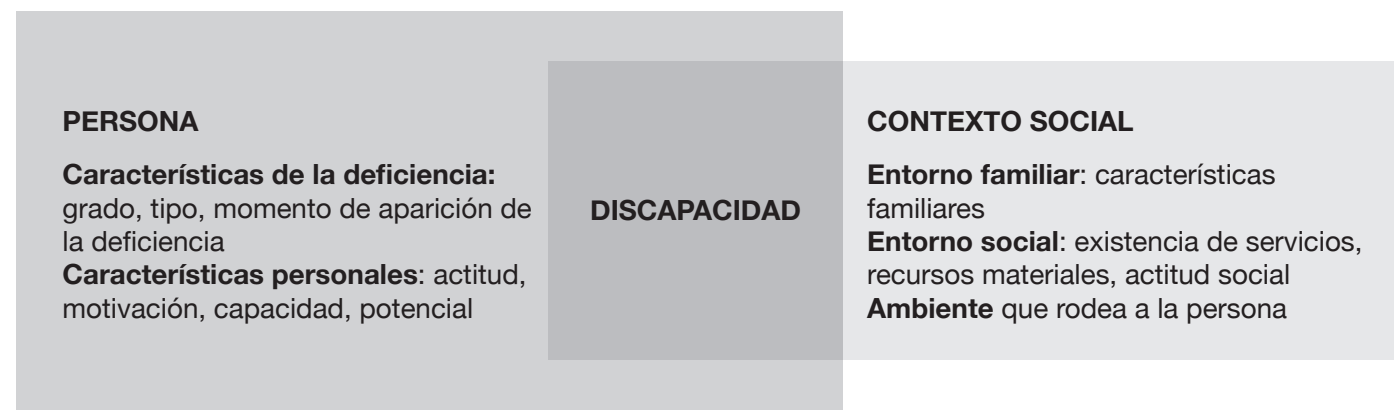

Fuente: Elaboración propia.

condiciones con respecto a otra persona sin discapacidad. Sin embargo, sin estos apoyos, la persona con discapacidad verá mermada su posibilidad de actuar. En este caso, no existe una falta de capacidad, sino de habilitación, por lo que la discapacidad de una persona no va a depender sólo de su deficiencia, sino de los apoyos, servicios y actitudes con los que se encuentre en su entorno para poder funcionar.

\section{Situación general de pobreza, discriminación múltiple y exclusión de las personas con discapacidad}

Más de mil millones de personas en el mundo (el I $5 \%$ de la población) viven con alguna forma de discapacidad, según las últimas estimaciones proporcionadas por la Organización Mundial de la Salud (201 I: 34). De esta cifra, un porcentaje desproporcionado, $80 \%$, vive en países pobres (ONU, 2006c: I). Algunos estudios del Banco Mundial afirman que " 500 millones de personas con discapacidad se encuentran entre las más pobres de entre los pobres" (Metts, 2000: 39), y se estima que representan "del I 5 al 20\% de los más pobres en países en desarrollo, encontrándose entre los grupos más desaventajados y que sufren mayor discriminación y vulnerabilidad" (Elwan, I999: I5-I6).

El número de personas con discapacidad va en aumento. Ello se debe, por una parte, al envejecimiento progresivo de la población y a que el riesgo de discapacidad es superior entre los adultos mayores; y por otra, al aumento mundial de enfermedades crónicas, tales como la diabetes, las enfermedades cardiovasculares, el cáncer y los trastornos de la salud mental. Las características de la discapacidad en un país concreto, están influidas por las tendencias en los problemas de salud y en los factores ambientales, y de otra índole, como los accidentes de tráfico, las catástrofes naturales, los conflictos, los hábitos alimentarios y el abuso de sustancias (OMS, 2OII: 38 ).

\section{La discapacidad afecta de manera}

desproporcionada a las poblaciones en situación de mayor vulnerabilidad. Los resultados de la Encuesta Mundial de la Salud indican que la prevalencia de la discapacidad es mayor en los países de ingresos bajos que en los países de ingresos más elevados. Los datos de las encuestas, a través de indicadores múltiples en los países seleccionados, ponen de manifiesto que los niños de las familias más pobres, aquellos que sufren discriminación y tienen un acceso limitado a los servicios sociales, incluyendo la educación en la primera 
infancia, los que tienen peso bajo y retraso del crecimiento, sufren castigos físicos graves por parte de sus padres y los que pertenecen a grupos étnicos minoritarios presentan un riesgo significativamente mayor de adquirir una discapacidad que los demás niños (OMS, 2OII: 4I). Las personas situadas en el quintil más pobre, las mujeres y los ancianos también presentan una mayor prevalencia de la discapacidad. Aquellas personas con pocos ingresos, desempleadas o con escasa formación académica, tienen mayor riesgo de adquirir una discapacidad (OMS, 20II: 296).

Además, la vulneración de los derechos de las personas con discapacidad lleva a éstas a una situación de discriminación, desigualdad y pobreza (ONU, 2006c: I-2). La discapacidad forma parte de la condición humana: casi todas las personas adquirirán algún tipo de discapacidad transitoria o permanente en algún momento de su vida, y las que lleguen a la senilidad experimentarán dificultades crecientes de funcionamiento. La discapacidad es compleja, y las intervenciones para superar las desventajas asociadas a ella son múltiples, sistémicas y varían según el contexto (OMS, 20II).

La situación de pobreza y los déficits son mayores en contextos de riesgo o emergencia humanitaria, en los que se agravan las condiciones de seguridad y protección de las personas con discapacidad, reduciéndose notablemente sus posibilidades de supervivencia. Se estima que existen 3,5 millones de personas refugiadas y desplazadas con discapacidad que viven en campos de refugiados y en los suburbios urbanos. Algunas de estas personas han vivido con una discapacidad toda su vida. Otras han adquirido una discapacidad a causa de un conflicto bélico. Estas personas se encuentran entre las más escondidas y olvidadas de entre las personas desplazadas. Permanecen excluidas de los servicios de asistencia generales, o simplemente, no pueden acceder a ellos como consecuencia de la existencia de barreras actitudinales, físicas y sociales. No se les reconoce su potencial para contribuir como partes activas de la sociedad (Women's Refugee Commission, 2009: I).
La pobreza de las personas con discapacidad no sólo se da en países de renta baja, sino también en países de mayor renta. Algunos estudios disponibles procedentes del Reino Unido afirman que las personas con discapacidad tienen el doble de posibilidades de vivir por debajo del umbral de la pobreza (hogares con ingresos inferiores al 60\% de la mediana de la renta nacional) que las personas sin discapacidad. Las cifras actuales sugieren que alrededor del I $6 \%$ de la población vive en un estado de pobreza relativa; sin embargo, cuando hablamos de personas con discapacidad, esta cifra sube al 30\% (Palmer et al., 2006).

La discapacidad debe considerarse como un problema de desarrollo, ya que hay un conjunto creciente de evidencia que demuestra que las personas con discapacidad se encuentran en peor situación socioeconómica y sufren más pobreza que las personas sin discapacidad, siendo éste uno de los desafíos más urgentes a los que se debe hacer frente hoy día (OMS, 20II).

3. Relación entre pobreza y discapacidad. Carácter multidimensional de la pobreza

La pobreza puede manifestarse como la privación existente en las vidas de las personas. No implica sólo la falta de bienestar material, sino la negación de las oportunidades para vivir una vida tolerable. A finales de los años noventa, los economistas y las instituciones de desarrollo llegaron a un acuerdo respecto al carácter multidimensional de la pobreza y a la idea de que el proceso de empobrecimiento es fruto de la compleja interacción de varios factores, entre los que se encuentra la discapacidad. Este carácter multidimensional y complejo de la pobreza, que va mucho más allá de la falta de ingresos o del consumo, quedó plasmado en un informe sobre desarrollo del Banco Mundial (200I), en el que se veían algunos cambios en cuanto al concepto y a 
la medición de la pobreza, al reconocerse las diferentes variables que influyen en ella ${ }^{2}$.

Existe una relación directa entre pobreza y discapacidad y entre discapacidad y pobreza, aunque sobre esta última afirmación es necesario llevar a cabo un proceso de investigación más profundo, que recoja datos contundentes, para poder diseñar políticas efectivas que reflejen este aspecto (Groce et al., 20I I). Por una parte, la pobreza produce discapacidad, que puede aparecer como consecuencia de una alimentación inadecuada o desnutrición, por falta de cuidados sanitarios -como cuidados perinatales, durante la maternidad-, o por causa de enfermedades y deficiencias que podían haberse evitado, siendo el problema principal la falta de prevención. Por otra parte, la discriminación que se deriva de la discapacidad lleva a la exclusión, la marginación, la falta de estudios, el desempleo; y todos estos factores aumentan el riesgo de pobreza. Las personas con discapacidad tienen más probabilidades de tener un nivel de ingresos por debajo del umbral de la pobreza, y tienen menos ahorros y propiedades que otros ciudadanos. Los estudios

Figura 2. Ciclo de la pobreza/discapacidad

INCLUSIÓN

(Ruptura del círculo)

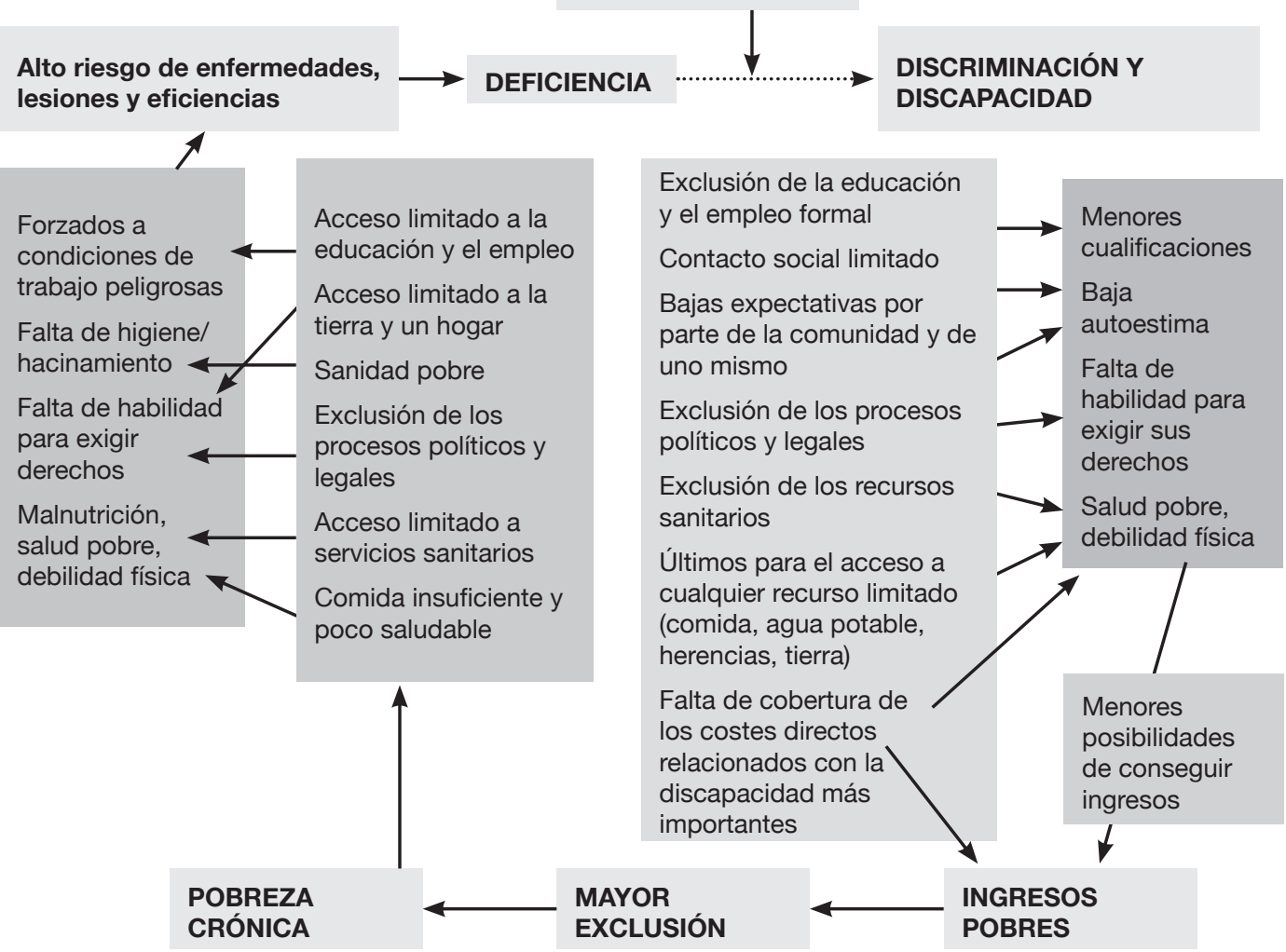

Fuente: Elaboración propia a partir de Yeo (2003).

2. El informe planteaba una reconsideración de la pobreza, en

la que se incluyen, como elementos constitutivos, la educación,

la salud, el riesgo, la vulnerabilidad, y el acceso a la toma de

decisiones en el plano local y nacional. 
de caso, indican que los mayores índices de discapacidad están asociados con altos índices de analfabetismo, estados nutricionales muy pobres, cobertura de vacunación e inmunización mínima, alto índice de VIH, peso bajo al nacer, mayor riesgo de sufrir violencia y abuso, y con mayor desempleo y menor movilidad ocupacional (Elwan, I999).

La Figura 2 presenta el ciclo existente entre la pobreza y la discapacidad, así como diversos factores que intervienen en el surgimiento de esta relación, mostrando además que la única forma de romper este círculo es mediante la inclusión. El concepto de inclusión hace hincapié en la necesidad de que el entorno realice los ajustes necesarios para asimilar a la persona con discapacidad, mediante el cambio y la rehabilitación del sistema social, con el objetivo de lograr acomodar a estas personas teniendo en cuenta sus derechos humanos, sociales y civiles. Sin embargo, esta inclusión no se produce, y a pesar del gran número de personas con discapacidad en situación de pobreza y de ser una población desproporcionadamente representada entre la población pobre, son 'invisibles' y se encuentran mayoritariamente ausentes en la definición e implimentación tanto de las agendas políticas como de la puesta en marcha de acciones en el ámbito de la cooperación para el desarrollo.

La pobreza de las personas con discapacidad se reconoce como el resultado de diferentes aspectos, tanto individuales como del ambiente en el que viven. Éstos están relacionados con aspectos materiales, como el empleo, los ingresos, los costes extraordinarios, las deudas, los bienes en propiedad, el consumo y la vivienda. También están vinculados con los servicios que las personas con discapacidad reciben con respecto a la educación, la salud, la rehabilitación y la inclusión social. Además, están las cuestiones ligadas a los elementos sociales y psicológicos de la pobreza, como la autoestima, el estigma, el contacto social, el matrimonio, la violencia, el poder y la autoridad. Existe, también, un elemento fundamental de carácter transversal a todos ellos, que es la accesibilidad.
Todos estos factores están interrelacionados $y$, en este sentido, sería un error estimar la pobreza de las personas con discapacidad considerando sólo y exclusivamente el nivel de ingresos y consumo obtenidos, puesto que es necesario tener en cuenta también las capacidades reales para convertir esos ingresos en bienestar (Sen, 2000).

En el estudio realizado por el Banco Mundial La voz de los pobres (I999) -que recoge las opiniones de 60.000 hombres y mujeres pobres de 60 países del mundo, a través de consultas realizadas a diversas personas que viven en condiciones muy diferentes, recopiladas en el que puede ser considerado como uno de los estudios participativos más amplios que se han realizado-, la discapacidad fue considerada, en un gran número de ocasiones, como una de las características que solían tener 'los muy pobres', y a las personas con discapacidad se las situaba entre los más excluidos, 'los más pobres de entre los pobres'. Por lo tanto, se concluía que las definiciones de pobreza y sus causas varían en función del género, la edad, la cultura y otros factores sociales y económicos, como la discapacidad (Narayan et al., I999; Narayan et al., 2000; Narayan y Petesch, 2002).

Desde el llamado enfoque de las capacidades, se desarrolló el índice de pobreza multidimensional's, que incluye un abanico de dimensiones que surgieron de ejercicios participativos llevados a cabo entre comunidades pobres y de un incipiente consenso internacional. Este índice complementa los métodos basados en la renta, al adoptar una perspectiva más amplia. Identifica las privaciones simultáneas que padecen los hogares en las tres dimensiones del índice de desarrollo humano y muestra la cantidad promedio de

3. El Índice de Pobreza Multidimensional es el producto de la incidencia de la pobreza multidimensional (la proporción de personas que son pobres en varias dimensiones) y del número promedio de privaciones que experimenta cada hogar pobre (la intensidad de su pobreza). Tiene las mismas tres dimensiones que el Índice de Desarrollo Humano (salud, educación y nivel de vida), reflejadas mediante diez indicadores (nutrición, mortalidad infantil, años de instrucción, matriculación escolar, combustible para cocinar, saneamiento, agua, electricidad, suelo pavimentado y bienes) [PNUD, 20I0]. 
personas pobres y las carencias que deben afrontar estas familias.

En Bangladés, por ejemplo, los pobres consideran que las personas ricas son aquellas que "tienen sus propias tierras y otras propiedades, animales de tiro para el cultivo, dinero para invertir, $y$ pueden permitirse comprar suficiente comida, llevar ropa buena, llevar a sus hijos al colegio, tener trabajo y movilidad, y están libres de la discapacidad" (Narayan y Petesch, 2002). Las personas que participaron en este estudio pusieron especial énfasis en este último factor. De forma similar, las personas que contribuyeron a un estudio participativo en Uganda manifestaron que la discapacidad y la pobreza se reforzaban mutuamente, y resaltaron la asociación entre discapacidad y pobreza crónica. Las personas con discapacidad se identificaron como las más pobres del país (Lwanga-Ntale, 2003).

Sin embargo, los participantes en un estudio del Banco Mundial hicieron notar que no siempre la discapacidad tiene que ir asociada a la pobreza. Por ejemplo, en un ejercicio de clasificación de la riqueza en Sierra Leona, se mostró que las personas del entorno local consideraban que, si las personas con discapacidad se veían provistas de las redes de apoyo adecuadas y tenían un trabajo con el que subsistir, su discapacidad no tenía por qué conducirles a la pobreza (Brock, I999).

En esta línea, una investigación realizada en Chuadanga (Bangladés) comparaba los niveles de pobreza basándose en tres indicadores: si los adultos o niños sufrían hambruna por una falta de recursos, si la familia estaba desalojada o sin hogar durante algunos periodos de tiempo, o si no les había sido posible pagar sus deudas. En casi todos los casos, los tres indicadores resultaban positivos para las familias en las que uno de sus miembros tenía una discapacidad (Chodwhury, 2005).

La pobreza limita las libertades humanas y priva a las personas de su dignidad, y en tal sentido, está asociada a los derechos humanos. El ejercicio efectivo del derecho al acceso a los alimentos, a la educación, a la libertad de expresión, a la participación, al empleo, a la cultura, el deporte y al ocio expande directamente la libertad humana y contribuye a que se produzca el desarrollo. En la medida en que las personas con discapacidad se vean privadas del acceso a estos derechos, se encontrarán sometidas a una situación de pobreza.

\section{La inclusión de la discapacidad en las teorías de desarrollo económico}

A lo largo de los años, la pobreza se ha definido de maneras diferentes. Los principales enfoques empleados para su definición y la aplicación de cada uno de ellos han dado lugar al diseño de políticas de desarrollo que han tenido diferentes consecuencias para las personas con discapacidad. Seguidamente, se realiza un recorrido por las principales teorías de desarrollo y cómo éstas han contribuido a la inclusión de la discapacidad como un aspecto que se ha de considerar para lograr un avance en el desarrollo económico.

\subsection{Teoría del crecimiento económico y el 'efecto goteo'}

La pobreza y el desarrollo han sido definidos y medidos de maneras muy diversas. Hasta los años noventa, los enfoques dominantes se han caracterizado por conceptualizar la pobreza y el desarrollo en términos de producto interior bruto per cápita, la seguridad alimentaria en términos de disponibilidad de alimentos y la pobreza en términos de falta de ingresos.

Las teorías sobre crecimiento económico sostienen que, si éste se mantiene, eventualmente 'goteará' a todos los miembros de la sociedad, con lo que se incrementarán los ingresos, la inversión y las oportunidades de empleo (Smith, I79I; Lewis, I954). Los resultados de las investigaciones para verificar que el crecimiento conduce a la reducción de la pobreza indican que 
no es así. El Banco Mundial, en su Informe de desarrollo mundial 2000/200I (200I), muestra cómo una fuerte desigualdad inicial disminuye los efectos positivos del crecimiento económico en la reducción de la pobreza. Ante una población desfavorecida, como en el caso de las personas con discapacidad, resulta imprescindible la elaboración de políticas de acción positiva para lograr reducir las diferencias existentes que proceden de una situación de partida desigual, de forma que todas las personas tengan las mismas oportunidades.

Otros autores, como Stiglitz (I974), también han criticado el 'efecto goteo' del crecimiento económico, haciendo hincapié en la existencia de información asimétrica e imperfecta en el mercado. Las personas pobres y, en concreto, las personas con discapacidad carecen de información suficiente para elegir aquellas opciones que maximizarían sus beneficios, entre otras cosas, por la falta de accesibilidad de la información para muchas personas con discapacidad.

Otra crítica al cálculo de la pobreza a través del producto nacional bruto per cápita es que, la mayor parte de las veces, se basa en encuestas realizadas a los hogares que no detectan las desigualdades producidas en su interior y la forma en que los ingresos son distribuidos entre sus miembros, que depende de una serie de variables como las mencionadas en el párrafo anterior (Sen, I988; Chowdhury, 2005).

Las desigualdades extremas de oportunidades y posibilidades de vida inciden de manera muy directa en lo que una persona está en condiciones de ser y de hacer, es decir, en las capacidades del ser humano. Por ejemplo, los niños que enfrentan mayor riesgo de morir por nacer con una discapacidad en un hogar de bajos ingresos, o por ser de sexo femenino y tener discapacidad tendrán claramente menos oportunidades de hacer realidad su potencial. Pero también existen poderosas razones instrumentales por las cuales debemos preocuparnos de la desigualdad: las profundas disparidades fundadas en la riqueza, la geografía, la existencia de discapacidad, el género o en el origen étnico son perniciosas tanto para el crecimiento como para la democracia y la cohesión social (PNUD, 2005).

La economía neoclásica se sustenta en el supuesto de la igualdad de oportunidades entre todos los actores (que no se produce) y excluye la influencia de factores ajenos a la economía, como puede ser la desigualdad de poder como palanca para la multiplicación del bienestar. No considera que la falta de participación política y la ausencia de representación en el proceso de toma de decisiones que sufren las personas con discapacidad se refleja en la invisibilidad y falta de consideración de sus demandas específicas en la puesta en marcha de políticas.

Las teorías que han considerado la falta de desarrollo económico como la principal causa de la pobreza han omitido cuestiones esenciales sobre la situación de las personas con discapacidad. Debido a que el 'efecto goteo' depende supuestamente del mercado y a que las personas con discapacidad se ven con frecuencia excluidas de éste o participan desde una posición desfavorable, resulta poco probable que se beneficien del crecimiento económico general.

La discriminación de las personas con discapacidad constituye otro factor no económico que explica la ausencia de beneficios monetarios para ellas. Las actitudes y creencias del empresariado, la calificación de las personas con discapacidad como incapaces y la falta de accesibilidad, entre otras, contribuyen a su exclusión sociolaboral. De hecho, la tasa de desempleo de las personas con discapacidad en países industrializados es de dos a tres veces más alta que la de las personas sin discapacidad (O’Reilly, 2003).

Adicionalmente, la 'invisibilidad' de las personas con discapacidad y, más especialmente de las mujeres con discapacidad, en las estadísticas oficiales dificulta el proceso de determinación de los efectos del desarrollo económico en estas personas e impide su adecuada inclusión en las de políticas de desarrollo. En algunos países pobres, muchos niños y niñas con discapacidad no son registrados al nacer o no se les proporciona 
un nombre, y por tanto, apenas hay datos sobre la existencia de hombres y mujeres con discapacidad. Todo esto indica que el crecimiento económico y la confianza en el efecto del 'goteo' no son estrategias adecuadas para combatir la pobreza de las personas con discapacidad.

\subsection{Teoría de las necesidades básicas}

Durante los años setenta, hubo consenso sobre el hecho de que el crecimiento económico no era condición suficiente para la eliminación de la pobreza, sino que era además necesario trabajar para este fin. En la Conferencia sobre Empleo Mundial (1976), se definieron las necesidades básicas, de acuerdo a la presencia de dos elementos:

Primero, incluyen determinados requerimientos mínimos para una familia para el consumo privado: comida adecuada, vivienda, ropa, lo mismo que ciertos utensilios del hogar y muebles. Segundo, incluyen servicios esenciales provistos por y para la comunidad en su más amplia escala, tales como agua potable, sanidad, transporte público y facilidades de salud y educación (OIT, I976: art. 2).

Sin embargo, la principal crítica al paradigma de las necesidades básicas es que corre el riesgo de permanecer exclusivamente ligado a promover el nivel de bienestar del individuo, sin tener en cuenta otros factores que favorecen su inclusión en la sociedad, culminando en programas de caridad y proyectos aislados dirigidos a mitigar la pobreza, en lugar de atacar sus causas estructurales. Bajo esta teoría de las necesidades básicas, las personas con discapacidad son calificadas como beneficiarias pasivas de los servicios proporcionados para satisfacer sus principales necesidades. La expansión del conocimiento y la salud de las personas tiene lugar con el único propósito de mejorar la economía (Fukuda-Parr y Shiva Kumar, 2003). Bajo esta filosofía, se promueven programas de salud y rehabilitación para las personas con discapacidad, pero sin una perspectiva real de inclusión de éstas en el mercado productivo.
Las personas con discapacidad son vistas como objetos pasivos, receptores de servicios sociales, pero no como sujetos de cambio y de aporte al valor de la economía a través del trabajo.

Hay dos puntos de vista sobre las necesidades básicas: uno objetivo, que define las necesidades humanas como cuantificables, medibles y comparables internacionalmente -en esta idea se basó el índice de desarrollo humano que surgió a principios de los años noventa (PNUD, I990)-; y otro subjetivo, que relaciona las necesidades humanas con un contexto histórico, social o cultural específico, y que, por tanto, hace que resulten difíciles de comparar y medir (Max-Neef, I986).

El nivel de necesidades básicas depende del nivel de desarrollo alcanzado y de los usos y costumbres de cada sociedad. En la determinación del concepto de bienestar, hay un elemento histórico y otro cultural muy importantes. Mientras que el primero permite la comparación de las necesidades de las personas con discapacidad dentro de un país - por ejemplo, las tasas de analfabetismo o el nivel de empleo-, el segundo, se centra en el vínculo entre desarrollo y cultura. La pobreza se define de distintas formas, dependiendo de qué necesidades son prioritarias en las diferentes culturas.

El principal problema al utilizar la teoría de las necesidades básicas para explicar la pobreza de las personas con discapacidad es que generalmente utiliza una perspectiva universal sobre lo que son las necesidades humanas, y una respuesta propia de los Gobiernos y de los donantes sobre cómo deben ser satisfechas. De esta forma, impide que las personas con discapacidad identifiquen sus propias prioridades de desarrollo, y desestima medidas específicas adecuadas a las necesidades diferentes de las personas con discapacidad, recurriendo a medidas uniformes.

\subsection{Teoría del desarrollo humano}

Siguiendo la perspectiva de las necesidades básicas y teniendo en cuenta el deterioro de la 
situación económica y social de la población pobre en muchos países en desarrollo en los años ochenta, Unicef lanzó la influyente propuesta de Ajuste con rostro humano, sugiriendo un modelo de ajuste compatible con el crecimiento y la equidad (Unicef, I987). Las políticas planteadas consistían en proteger el gasto público para los servicios sociales, como la educación y la salud, de los recortes generales en los presupuestos públicos. El Programa de Naciones Unidas para el Desarrollo (PNUD) fue más allá y puso en práctica la teoría del desarrollo humano, que afirma que éste implica permitir a las personas que tengan una vida que valoren y puedan aprovechar todo su potencial humano. En I990, Mahbub ul Haq, en el primer Informe de desarrollo humano, escribió:

El primer objetivo del desarrollo humano es el de crear un entorno de posibilidades en el que las personas puedan tener una vida larga, saludable y creativa. Las personas son la riqueza de las naciones, aunque en la mayoría de los casos esto se olvida y tendemos a igualar la riqueza económica con el bienestar humano. Estos dos conceptos, sin embargo, no son equiparables, como lo demuestra el reciente crecimiento económico que ha tenido lugar y que, sin embargo, ha ido acompañado de desigualdad social, pobreza y falta de fortalecimiento político (PNUD, 2006: 263)

Esta teoría sostiene que las políticas no se pueden centrar únicamente en la generación de ingresos. Tampoco el crecimiento de ingresos per cápita puede ser el criterio dominante para juzgar el estado de la sociedad. El desarrollo humano está motivado por una preocupación por la libertad, el bienestar y la dignidad de los individuos.

El PNUD perfeccionó el concepto en sus sucesivos informes sobre desarrollo humano, a partir de los años noventa, que incluyen indicadores sociales para intentar captar la dimensión no económica de la pobreza. Bajo este nuevo enfoque, se elaboró el índice de desarrollo humano. La amplitud y capacidad de este enfoque contrastan con la constricción y especificidad del índice de desarrollo humano en sí mismo. Medir el bienestar no es tarea fácil. Es un concepto con múltiples dimensiones relacionadas con el carácter de las necesidades humanas, y que varía según el tiempo y el contexto. Sin embargo, hasta ahora, no existe un índice que comprenda las diferencias entre las distintas poblaciones o las características específicas de los grupos más desfavorecidos, como en el caso de la discapacidad (Sen, 2004).

De esta manera, estos índices ocultan la exclusión económica y social de las personas con discapacidad y, en la medida en que las poblaciones más desfavorecidas no son tenidas en cuenta, suponen un freno al progreso y al desarrollo. El criterio esencial para medir el progreso es la calidad de vida de los individuos, y ésta no sólo se puede valorar en función de los ingresos de una persona, sino de las oportunidades reales con las que cuenta para emplearlos en su desarrollo dentro del contexto en el que se encuentra. Los ingresos y las posibilidades que le brinda el entorno deben ser suficientes para poder acceder a la educación, gozar de buena salud, y poder participar de una vida política y en sociedad sin estar excluidos en ningún sentido. La persona es, ante todo, un ser social y político, y, como tal, debe tener un sentimiento de pertenencia al entorno y a la sociedad si quiere alcanzar el desarrollo (Sen, 2000).

Aunque la renta puede parecer un buen indicador de la calidad de vida, plantea dos problemas principales. Primero, que no está correlacionada con el acceso a los bienes públicos. Y segundo, que la forma en que los individuos pueden convertir su renta en un determinado nivel de vida varía. Existen diversas causas de variación en el nexo existente entre la capacidad de pago y el nivel de vida. Una de estas causas es la discapacidad. En este último caso, cuando en la renta no se hacen los ajustes pertinentes, se subestima el problema que tienen las personas con discapacidad por tener ingresos bajos o por soportar unos costes extraordinarios adicionales que reducen su acceso a los bienes y servicios disponibles para toda la población general (Malo y Dávila, 2006).

Amartya Sen apunta que hay grandes diferencias en las necesidades de los individuos y llama la 
atención sobre cinco categorías amplias en torno a las diferencias existentes en la conversión de la renta del hogar en bienestar social: las diferencias personales (el género o la discapacidad, entre otras), la diversidad medioambiental (el clima o la epidemiología), el marco económico (la disponibilidad de bienes públicos), las normas sociales (la determinación de las posesiones necesarias para ser socialmente aceptado) y la distribución de la renta en el interior del hogar.

La privación no se puede medir sólo en términos de privación económica, sino que es necesario medir el grado de adversidad (Sen, 2000). A los hogares en los que vive una persona con discapacidad se les tendrá que aplicar una escala de equivalencia, de forma que los ingresos se computen como menores a los inicialmente establecidos.

En lo que se refiere a la distribución de la riqueza, la discapacidad y el género son factores clave para determinar cómo se reparten los ingresos en el hogar y el gasto que desde el hogar se realiza en habilitación, rehabilitación y tratamientos médicos para la persona con discapacidad. Algunas fuentes centradas en estudiar la discapacidad en países pobres muestran que el gasto que realizan los hombres con discapacidad es mucho mayor que el de las mujeres. Las mujeres con discapacidad pasan inadvertidas por parte de la familia, y ellas mismas posponen cualquier tipo de intervención para la mejora de su bienestar (intervención médica, programa de rehabilitación, programa educativo) para invertir ese dinero en el bienestar de la familia. En este sentido, las mujeres con discapacidad sin ingresos se encuentran las últimas dentro de la lista de prioridades del hogar, y sólo los hombres con discapacidad que tienen un puesto de trabajo pueden llegar a recibir tratamientos que requieran operaciones quirúrgicas (Chowdhury, 2005).

Existen numerosos tipos de privación de libertad y las personas con discapacidad se ven sometidas a muchos de ellos. En países pobres sufren desnutrición, falta de asistencia sanitaria, falta de acceso al agua limpia, e incluso la propia discapacidad puede ser un resultado de su pobreza. Pero en los países de mayor crecimiento económico, a menudo se ven excluidos, en desigualdad de condiciones, sin oportunidades para acceder a la educación, a un empleo digno y, en definitiva, sus libertades y sus derechos se ven vulnerados, lo que afecta al desarrollo de sus capacidades y, por ende, al desarrollo económico.

El aumento de la libertad mejora la capacidad de los individuos para ayudarse a sí mismos, y por lo tanto, para influir en el mundo, lo cual provoca cambios y aporta al desarrollo. Éste es un hecho que durante mucho tiempo se ha obviado en referencia a las personas con discapacidad y, aunque en este momento, a escala internacional y nacional, en muchos países ya se reconoce, a través de la legislación y la filosofía política, todavía faltan las herramientas y recursos necesarios para que esto sea una realidad y las personas con discapacidad puedan utilizar sus capacidades para convertirse en agentes de desarrollo.

Dentro de la teoría del desarrollo, han sido fundamentales los conceptos de empoderamiento y fomento de las capacidades, que han dado lugar a la teoría del empoderamiento y la teoría de las capacidades.

\subsubsection{Teoría del empoderamiento}

La filosofía del empoderamiento tiene su origen en el enfoque de la educación popular desarrollada a partir del trabajo de Paulo Freire $^{4}$ en los años sesenta. El empoderamiento es aplicable a todos los grupos excluidos o marginados. Así, la importancia del empoderamiento de las personas con discapacidad como parte del avance en el desarrollo ha sido reconocida por el secretario general de Naciones Unidas:

\footnotetext{
4. Llama la atención sobre los procesos mediante los cuales las personas excluidas se liberan de las estructuras que limitan su participación social, intelectual y política. Este autor plantea un continuo que va desde la forma de conciencia no reflexiva, en que la persona es objeto y se encuentra sin capacidad de selección, a la visión de conciencia crítica, en la cual se pasa a una persona sujeto que se encuentra con la realidad y participa con capacidad de tomar decisiones y transformar (Freire, I986).
} 
La experiencia demuestra que cuando se faculta a las personas con discapacidad para participar en el proceso de desarrollo y para dirigirlo, la comunidad entera se vuelve receptiva. La participación de las personas con discapacidad crea oportunidades para toda la ciudadanía, tenga o no una discapacidad. El mensaje para los Objetivos de Desarrollo del Milenio (ODM) es claro: centrar nuestra labor en las personas con discapacidad y en sus comunidades es una forma segura de impulsar el programa de desarrollo (ONU, 2009: I).

Desde el enfoque de los derechos humanos, el desarrollo de las personas con discapacidad implica la autorrepresentación. El crecimiento de un movimiento de la discapacidad democrático y representativo es una forma de garantizar que las respuestas del Gobierno sean adecuadas para cubrir las necesidades y responder a los derechos de las personas con discapacidad. Hay que asegurarse de que los grupos a los que van dirigidas las políticas están implicados en la planificación, implementación y monitorización de todo el trabajo de desarrollo, así como tomar medidas para eliminar barreras para la participación, y combatir las prácticas, políticas, actitudes y ambientes discriminatorios.

Las teorías que se dedican específicamente a abordar las causas estructurales de la pobreza de las personas con discapacidad enfatizan que la exclusión, la discriminación y la desigualdad son causas determinantes de su situación de pobreza y exclusión. Las demandas de las organizaciones de las personas con discapacidad, así como las afirmaciones de las distintas instituciones de derechos humanos, muestran la importancia que éstas otorgan a poder ejercer una participación mayor y más equitativa en la economía y en la toma de decisiones, a todos los niveles, así como la posibilidad de determinar su propio proceso de desarrollo basándose en sus conocimientos, experiencias e inclusión en la sociedad. La teoría del empoderamiento puede aplicarse a los procesos de desarrollo basados en la autodeterminación de las personas con discapacidad, así como en aquellos que proponen su participación más equitativa en el proceso de desarrollo general.

\subsubsection{El enfoque de las capacidades}

El enfoque de las capacidades defiende que la estimación del desarrollo mediante la renta es insuficiente. Éste tiene que ver, más bien, con las cosas que las personas pueden realmente hacer o ser (los llamados funcionamientos), así como con las capacidades de que disponen entendidas como las oportunidades para elegir llevar una u otra clase de vida.

Los recursos disponibles no proporcionan suficiente información, puesto que su aprovechamiento varía según circunstancias personales -como la edad, la salud o la existencia de una discapacidad- y socioculturales -como la educación, el capital social o el entorno donde se desenvuelve-. A este respecto, hay que tener en cuenta que una persona con discapacidad necesitará más recursos que una persona sin ella para poder lograr su capacitación personal y poder funcionar al igual que los demás en la realización de sus actividades cotidianas.

Este paradigma se centra en acentuar las capacidades en lugar de eliminar las discapacidades. La discapacidad salta del ámbito de la medicina al de las políticas públicas, las cuales deben incorporar transversalmente y con medidas de acción positiva los derechos de las personas con discapacidad. Es necesario el desarrollo de políticas, programas, medidas y herramientas que promuevan la inclusión de éstas. Según las teorías sobre discapacidad basadas en el modelo social y de derechos humanos, la única forma de romper el círculo existente entre discapacidad y pobreza es mediante la inclusión.

El modelo social de la discapacidad y el enfoque de las capacidades comparten el reconocimiento de la existencia de barreras sociales para lograr la igualdad, y adjudican un papel central a la discriminación como origen de la exclusión. Cuando desde ambas perspectivas se trata de diseñar un plan de actuación, éstas se centran en la eliminación 
de obstáculos. En este sentido, Nussbaum afirma que los Estados tienen la obligación de promover el establecimiento de una base social para conseguir el desarrollo de las capacidades humanas centrales (Balyes, 2002).

Amartya Sen propone la incorporación de las habilitaciones 5 individuales, el funcionamiento, las oportunidades, capacidades, libertades y derechos como parte fundamental de la base conceptual de las ciencias económicas y de la elección social. Los recursos tienen un valor instrumental, al ser requisitos indispensables para obtener capacidad. Una persona está habilitada respecto a ciertos recursos cuando puede disponer de su uso. Por otra parte, la habilitación puede producirse también a través de los servicios. Por ejemplo, podemos estar habilitados para obtener cierta cantidad de alimento porque disponemos de dinero para adquirirla en el mercado. En cambio, no estaríamos habilitados si meramente dependiéramos de la beneficencia. A este respecto, Sen considera que el dinero no es equivalente a la capacitación, debido a las variaciones de precios, el nivel de la oferta, la facilidad de acceso a los mercados, o a las restricciones legales y culturales para conseguir ciertos recursos. El enfoque de las capacidades persigue determinar, a partir de las capacitaciones iniciales y de las de intercambio, cuál es el conjunto de capacitaciones.

A modo de ejemplo, una persona ciega estará habilitada para conseguir cierta cantidad de alimento si tiene dinero, pero necesitará además una habilitación mayor que otras personas, puesto que, para comprar el alimento que precisa, será esencial que existan unas condiciones de accesibilidad que, para las personas ciegas, son

5. En este contexto, entitlement se traduce como 'habilitación' en el sentido de 'dar derecho a algo', que es una de las acepciones del término en el Diccionario de la Real Academia Española. Entitlement es un término formal que significa 'derecho' o 'título' (como en 'título de propiedad'). La expresión to be entitled to something significa 'tener derecho a algo o la capacidad para algo'. Debe notarse que se refiere a una autorización formal, quizá legalmente establecida, y no a una exigencia de justicia. No se emplea la palabra 'derecho', porque se considera que ésta tiene otras connotaciones y sería adecuada para traducir la palabra right, que no fue empleada por Sen. diferentes que para el resto de la población. $\mathrm{Al}$ no existir estas condiciones de accesibilidad adecuadas, las personas ciegas obtendrán esta capacitación para adquirir el alimento de distintas maneras, con más tiempo o esfuerzo, con el apoyo de familiares o amigos, o con más dinero por la imposibilidad de comparar precios de manera directa. Por lo tanto, el conjunto de capacitaciones necesario será mayor ${ }^{6}$.

Por una parte, debemos interpretar que las habilitaciones son derechos que estructuran las relaciones entre un sujeto y los demás en referencia a ciertos bienes, y aunque tales derechos no sean exigencias morales, sino facultades positivas, están en la línea de los derechos sociales y económicos, cuya garantía es característica del Estado de bienestar (Cejudo, 2007). Sin embargo, tales derechos no garantizan que las habilitaciones directas y de intercambio permitan, en circunstancias adversas, el control de los recursos mínimos para sobrevivir.

El análisis de Sen distingue un nivel intermedio entre las habilitaciones y las capacidades. Ser libre es ser capaz, y para eso hace falta estar habilitado. Ahora bien, ¿ser capaz de qué? La respuesta es ser capaz de funcionar. Los funcionamientos hacen referencia a las acciones que el sujeto lleva a cabo, o a la situación en la que se encuentra, gracias a sus habilitaciones y al uso que pueda hacer de ellas, por ejemplo, alimentarse, viajar, tener un trabajo, una vivienda, descansar, obtener una educación o estar saludable (Robeyns, 2005).

Los funcionamientos proporcionan una concepción novedosa del bienestar, en la que éste ya no consiste ni en la utilidad ni en la cuantía de los recursos. Dentro del marco formal de la economía tradicional, se han empleado criterios de bienestar como el concepto de utilidad. Este concepto se ha interpretado generalmente en términos de felicidad y sufrimiento, placer

6. Tal y como muestra un estudio realizado en la localidad de Madrid, que concluyó que, por diferentes motivos, en lo que se refiere a ir de compras, todas las personas con problemas visuales encuentran dificultades y gastan un $30 \%$ adicional al resto de los consumidores para suplir la falta de accesibilidad de los patrones de consumo existentes (Martínez Ríos, 2006). 
individual o cumplimiento de los deseos. El utilitarismo se caracteriza por la búsqueda de las consecuencias buenas que una acción tiene para el individuo y la sociedad. La evaluación de la acción está determinada por los resultados que obtiene. Tanto Bentham como Mill se vieron influidos por la corriente empirista que dominaba el pensamiento particularmente en las islas británicas: "la mayor felicidad para el mayor número" (Beauchamp, I982: I2).

Sin embargo, desde la perspectiva del enfoque de las capacidades se critica el empleo del concepto de utilidad como base para evaluar y comparar los intereses humanos y las interpretaciones de eficiencia económica y optimización social? La vida de la persona está contemplada por un conjunto de funcionamientos (estar alimentado, sano, protegido; leer, estudiar, trabajar, viajar, vivir en sociedad y participar), el cual delimita el 'estado general' de la persona y su forma de vivir.

El utilitarismo sacrifica el bien de la minoría y, en este caso, el de las personas con discapacidad, por la tiranía de la mayoría. Bajo los supuestos del utilitarismo, se defendería la normalización sin tener en cuenta las necesidades concretas de las personas con discapacidad y, por lo tanto, sin prever el coste adicional que supondría las adaptaciones específicas para un tipo de discapacidad, puesto que el empleo de recursos en este sentido no estaría beneficiando a la mayoría. Por ejemplo, no sería justificable la fabricación de autobuses con rampas, que suponen el empleo de más recursos, puesto que éstas sólo van a ser utilizadas por un porcentaje menor de la población, representada por personas usuarias de sillas de ruedas o carritos de bebés, entre otras, que verían vulnerado su derecho a la movilidad.

El enfoque de las capacidades mantiene que la relación entre un recurso y el funcionamiento

\footnotetext{
7. El utilitarismo ha dado lugar a corrientes como la normalización, que incluyen procesos cuyo objetivo es la estandarización a fin de maximizar la utilidad para el mayor número de personas. Desde este tipo de procesos, las personas con discapacidad quedan en muchas ocasiones excluidas, por no tener unas necesidades estándares. En este sentido, la normalización debe ser sustituida por filosofías entre cuyos principios se encuentre el diseño para todos o la accesibilidad universal, para que ninguna persona quede al margen.
}

para lograr ciertos estados y formas de hacer está influida por tres grupos de factores de intercambio. El primero, los factores de intercambio personales (como el metabolismo, la condición física, el sexo, las habilidades de lectura, la inteligencia), influyen sobre cómo una persona puede convertir las características de un recurso en un funcionamiento. Por ejemplo, si una persona tiene una deficiencia física, un coche (no adaptado) puede resultarle de muy poca utilidad para conseguir el funcionamiento de la movilidad.

Los factores de intercambio sociales (tales como las políticas públicas, normas sociales, prácticas discriminatorias, roles de género, jerarquías sociales y relaciones de poder) y los factores de intercambio medioambientales (entre ellos, el clima o la localización geográfica) juegan un papel muy importante en la conversión de las características del recurso y el funcionamiento individual. Por ejemplo, la misma persona con una deficiencia física podrá conseguir que un coche le proporcione gran utilidad y un funcionamiento óptimo si en el entorno en el que vive existen ayudas técnicas para adaptar el coche a su discapacidad (por ejemplo, adaptaciones en la cabina, el volante, el embrague, el freno o el acelerador), y aún más, si el Estado le proporciona ayuda financiera o subvenciones para realizar estas adaptaciones. Sin embargo, si la persona con una deficiencia física vive en un entorno en el que estas adaptaciones no existen, o donde socialmente se considera que una persona en esa situación no es capaz de conducir, la persona con discapacidad se verá imposibilitada para utilizar este recurso y conseguir su funcionamiento. Su capacidad se verá anulada por no estar habilitada para funcionar, al existir factores de intercambio desfavorables.

\section{Los costes extraordinarios de la discapacidad}

El enfoque de las capacidades cubre todas las dimensiones del bienestar humano. Por 
otra parte, los servicios y los recursos no son el único modo en el que las personas pueden desarrollar sus capacidades. Hay otros factores que funcionan como insumos en la creación o expansión de capacidades, como pueden ser los factores de intercambio sociales definidos de una manera amplia. Las circunstancias (tanto materiales como no) dan forma al conjunto de oportunidades que tienen las personas, y las circunstancias que influyen en las elecciones que éstas pueden realizar sobre el conjunto de capacidades deben ocupar un lugar central en la evaluación de las capacidades. Sería necesario prestar atención a las normas sociales $\mathrm{y}$ tradiciones que condicionan las preferencias de las personas con discapacidad y que influyen en sus aspiraciones y elecciones efectivas. Hay que enfatizar la necesidad de analizar el contexto en el que la producción económica y la interacción social tienen lugar, y hasta qué punto las circunstancias en las que las personas pueden llevar a cabo sus elecciones son justas y habilitadoras.

Es extremadamente importante distinguir entre dos tipos de 'desventajas' que tienden a acompañar a la discapacidad, las cuales podrían llamarse 'desventaja en la obtención de ingresos' y 'desventaja en el intercambio', respectivamente. Para una persona con discapacidad, es habitualmente más difícil obtener un empleo y mantenerlo, y suele recibir menores ingresos por su trabajo que una persona sin discapacidad. Pero esto es sólo parte del problema. Además, para realizar las mismas actividades que una persona sin discapacidad, una persona con discapacidad necesita mayores ingresos. Por ejemplo, para movilizarse de manera independiente una persona ciega necesitará un bastón, un perro guía, el acompañamiento de otra persona que le pueda guiar, un GPS parlante o viajar en taxi para ir a determinados lugares desconocidos. La obtención de todas estas ayudas implicará un desembolso económico que le llevará a una situación de desventaja en el intercambio. La desventaja en el intercambio se refiere a los obstáculos y dificultades que una persona con discapacidad tiene para convertir su dinero en calidad de vida. Por lo tanto, las personas con discapacidad sufren ambos problemas en el intercambio.
Las desventajas en la obtención de ingresos, así como las desventajas en el intercambio, pueden expresarse en la existencia de costes extraordinarios producidos por la discapacidad. En este sentido, teniendo en cuenta la forma en que se producen estos costes extraordinarios, la primera desventaja en la obtención de ingresos se traduce en la existencia de costes extraordinarios indirectos que implican que las personas con discapacidad suelen tener ingresos por debajo de los de las personas sin discapacidad, ya que suelen estar desempleadas o tener trabajos de menor cualificación. Por otra parte, la desventaja en los intercambios se produce por un nivel de necesidad extraordinaria como resultado de la discapacidad que no es cubierta socialmente y conduce a la existencia de costes extraordinarios directos.

Algunos resultados de investigaciones realizadas sobre los índices de pobreza del Reino Unido muestran la relación de la pobreza con respecto a la desventaja en el intercambio. Marcando el umbral de pobreza en el $60 \%$ de la mediana nacional de ingresos, Kuklys encontró que el I $7,87 \%$ de las personas viven en familias cuyos ingresos están por debajo del umbral de la pobreza. Si prestamos atención a las personas que viven en familias en la que alguno de sus miembros tiene una discapacidad, el porcentaje de personas que viven con un nivel de ingresos inferior al umbral de la pobreza es del 23,07\% (Kuklys, 2005: 98).

Esta diferencia de cinco puntos porcentuales reflejaría la enorme desventaja en la obtención de ingresos asociada con la discapacidad y su necesidad de apoyo. Si introducimos ahora el concepto de desventaja en el intercambio y se toma nota de la necesidad de mayores ingresos para aminorar las desventajas de la discapacidad, la proporción de individuos en las familias con algún miembro con discapacidad aumenta hasta el $47,43 \%$, una brecha de casi el $30 \%$ sobre la cantidad de individuos que viven bajo la línea de pobreza en la población en general (19,83\%). Para ver la comparación de otro modo, del $30 \%$ extra que señala la desventaja de los individuos que viven en familias con personas con discapacidad, una cuarta parte puede ser 
atribuida a la desventaja en la obtención de ingresos, y tres cuartas partes, a la desventaja en el intercambio. Debido a que la prevalencia de la discapacidad es relativamente menor en el Reino Unido que en otros países con renta más baja, tomar en cuenta las desventajas en el intercambio o de los costes extraordinarios de las personas con discapacidad en países pobres tendría un efecto general mucho más acusado. Ignorar la desventaja en el intercambio o los costes extraordinarios producidos por la discapacidad, como suelen hacer las mediciones de pobreza basadas en los ingresos, tiene el efecto de distorsionar enormemente el nivel de pobreza en familias con uno o más miembros con discapacidad (Sen, 2004).

Adicionalmente, algunos de los ingredientes necesarios para obtener una buena calidad de vida no provienen solamente del ingreso personal, sino de las condiciones sociales, tales como la provisión de educación pública o los servicios a la ciudadanía. A muchas niñas y niños con discapacidad se les niega, de hecho, el acceso razonable a la educación primaria en muchos países pobres, debido a la ausencia de las adaptaciones necesarias para la diversidad de personas con discapacidad.

Se ha estimado que, de los roo millones o más de niños que no reciben educación en el mundo, alrededor de 40 millones tienen una discapacidad de algún tipo (Sen, 2004). La mayoría de las escuelas, particularmente en los países de menor renta, se construyen sin contemplar medidas de accesibilidad (por ejemplo, rampas para el acceso de niños y niñas con discapacidades físicas, o accesibilidad de la información o comunicación, entre otras), y la mayoría de los maestros carecen de la formación necesaria para trabajar con niños que tienen discapacidades de diferentes tipos (entrenamiento en el sistema braille, lengua de signos y ausencia de curricula educativos adaptados a discapacidades que suponen dificultades en el aprendizaje, entre otras). A este respecto, la desventaja en el intercambio o los costes extraordinarios de la discapacidad surgen también al intentar convertir los servicios en oportunidades que sean realmente utilizables.
Por último, es importante señalar también que las vidas de las personas con discapacidad pueden verse más limitadas debido a actitudes sociales desfavorables hacia la discapacidad, o a la aplicación de legislación o normativa discriminatoria. Esto es, en sí mismo, un factor más del que surgen desventajas en el intercambio o costes extraordinarios de la discapacidad, pero a estas adversidades deben sumársele las posibilidades reales de maltrato al que son sometidas las personas con discapacidad frecuentemente (Sen, 2004). En este sentido, hay evidencias claras de que la población con discapacidad, en especial las mujeres con discapacidad, tienen incluso un mayor riesgo, en muchas situaciones, de adquirir el VIH y otras infecciones, debido al abuso físico y sexual. Algunas encuestas que se han realizado en Europa, Norteamérica y Australia mostraron que "más de la mitad de las mujeres con discapacidad han experimentado abuso físico, mientras que para las mujeres sin discapacidad esta cifra se reduce a un tercio" (ONU, 2006: 56).

La lección básica es suficientemente clara: los costes extraordinarios derivados de la discapacidad suponen un factor de pobreza que debe ser tenido en cuenta para poder valorar adecuadamente la calidad de vida y bienestar de las personas con discapacidad. En este sentido, el enfoque de las capacidades justifica la existencia de costes extraordinarios de la discapacidad como factor de pobreza. Los costes de la discapacidad están presentes en todas las áreas de la vida y, en muchas ocasiones, son el fruto de los valores culturales, de la forma de concebir la discapacidad en el entorno en el que la persona se encuentra o de actitudes discriminatorias. Además, las consecuencias de estos costes son muy diferentes dependiendo del apoyo de la comunidad o de los servicios existentes para las personas con discapacidad. Los estudios nos muestran que cuanto menor es la inclusión, la accesibilidad de los entornos y los servicios disponibles, mayores son los costes extraordinarios de la discapacidad. 


\section{Los costes extraordinarios de la discapacidad en diferentes estudios}

Existen muchas formas de aproximarse a la delimitación del concepto de coste extraordinario de la discapacidad desde un punto de vista económico. Una consiste en considerar la pérdida de ganancias que las personas con discapacidad pueden experimentar, o a la que sus familiares se enfrentan como resultado de tener que dejar de trabajar para poder cuidarlos, lo que los economistas denominan costes de oportunidad. Otra es valorar el coste que, para las organizaciones públicas o voluntarias especializadas, tiene la provisión de servicios a este colectivo. Por último, una tercera forma radica en cuantificar el gasto extraordinario al que se tienen que enfrentar las personas con discapacidad para poder funcionar (Berthoud, I993).

Los costes de la discapacidad se pueden definir como la cantidad de dinero adicional que necesita una persona con discapacidad para alcanzar un nivel de vida que pueda considerarse similar al de una persona sin discapacidad en las mismas circunstancias (Indecon, 2004). La medición de los costes de la discapacidad no está exenta de dificultades, tanto en un sentido metodológico como en el conceptual. Es necesario llegar a un acuerdo operativo sobre lo que significa coste extraordinario. Los estudios disponibles han empleado diferentes enfoques para llegar a su cuantificación y conceptualización. Algunos siguen un enfoque que delimita este concepto a partir de la medición del gasto real que la persona efectúa por motivos de discapacidad. Otros adoptan un presupuesto específico que es acordado a partir de las necesidades básicas expresadas por personas representativas de la población. Una tercera forma se centra en estudiar la privación material experimentada por las personas con discapacidad y cómo afecta a su nivel de vida (Tibble, 2005).

Existen cuatro factores que influyen en el gasto extraordinario que una persona con discapacidad debe realizar para mantener el mismo nivel de vida que otra sin discapacidad en las mismas circunstancias: el nivel de necesidad extraordinaria como resultado de su discapacidad; el nivel de provisión de servicios sociales, prestaciones de la Seguridad Social, prestaciones económicas y exenciones fiscales existentes para cubrir esa necesidad específica derivada de la discapacidad; el efecto de la discapacidad en los ingresos, ya que, las personas con discapacidad suelen tener ingresos por debajo de los de las personas sin discapacidad, suelen estar desempleadas o tener trabajos de menor cualificación; y por último, el grado de inclusión de la persona con discapacidad en la sociedad (Tibble, 2005). Cuanto menos obstáculos se encuentren, menor será el gasto extraordinario (Martínez Ríos, 20II).

A través de la revisión de la literatura sobre los estudios para medir el gasto extraordinario procedente de la discapacidad, cabe indicar que existen estimaciones de los costes muy diferentes que dependen de la metodología empleada en la estimación y del grupo de muestra analizado, no existiendo un consenso sobre cuál es la mejor metodología para la estimación de los costes de la discapacidad (Indecon, 2004). Se puede concluir dentro de este panorama general diciendo que existe un patrón común emergente de todos estos estudios a escala internacional:

- La discapacidad produce en general un mayor coste de vida. Este coste extraordinario puede ser modesto cuando la discapacidad es leve, pero bastante alto cuando la severidad es mayor.

- El coste varía teniendo en cuenta la naturaleza de la discapacidad y el grado de severidad, así como en relación con otros muchos factores personales, ambientales y circunstanciales.

- $\quad$ El coste extraordinario se establece en función de las barreras existentes (actitudinales, sociales y físicas).

- Teniendo en cuenta la variabilidad de los costes, es más significativo hablar de un abanico de costes que de un coste medio. 
Cuadro 1. Resumen de estudios sobre los costes de la discapacidad

\begin{tabular}{|c|c|c|c|c|c|c|c|}
\hline \multirow{2}{*}{ Estudio } & \multirow{2}{*}{ Año } & \multirow{2}{*}{ Tipo } & \multirow{2}{*}{$\begin{array}{l}\text { Muestra }\left(n^{\circ}\right. \\
\text { personas) }\end{array}$} & \multirow{2}{*}{$\begin{array}{l}\text { Naturaleza de la } \\
\text { discapacidad }\end{array}$} & \multicolumn{3}{|c|}{ Coste extra $(€)$} \\
\hline & & & & & Mínimo & Máximo & Medio \\
\hline Hyman- & 1975 & Encuesta & 56 & \begin{tabular}{|l|}
$\begin{array}{l}\text { Usuarios de sillas } \\
\text { de ruedas }\end{array}$ \\
\end{tabular} & 7 & 591 & 138 \\
\hline Stowell y Day & 1983 & Encuesta & 14 & & - & - & 11 \\
\hline Buckle & 1984 & Encuesta & 133 & \begin{tabular}{|l} 
Discapacidad \\
intelectual
\end{tabular} & 4 & 251 & 62 \\
\hline $\begin{array}{l}\text { OPCS, Martin y } \\
\text { White }\end{array}$ & 1985 & Encuesta & 9.982 & \begin{tabular}{|l} 
Adultos con \\
discapacidad
\end{tabular} & 9 & 37 & 19 \\
\hline $\begin{array}{l}\text { OPCS, Smith y } \\
\text { Robus }\end{array}$ & 1985 & Encuesta & 1.200 & \begin{tabular}{|l|} 
Niños con \\
discapacidad
\end{tabular} & - & 38 & 20 \\
\hline DIG & 1988 & Encuesta & 87 & $\begin{array}{l}\text { Solicitantes del } \\
\text { Fondo de Vida } \\
\text { Independiente } \\
\end{array}$ & - & 193 & 133 \\
\hline OPCS. Mckay & 1990 & Encuesta & - & \begin{tabular}{|l|} 
Adultos de \\
la OPCS \\
semejantes a \\
DIG $^{\mathrm{b}}$ \\
\end{tabular} & - & - & 39 \\
\hline Walsh y Chapel & 1999 & Encuesta & 1.000 & $\begin{array}{l}\text { Apoyo a } \\
\text { Pensionistas con } \\
\text { discapacidad } \\
\end{array}$ & - & - & 11 \\
\hline Hughes y Purdy & 1999 & Encuesta & 200 & $\begin{array}{l}\text { Personas con } \\
\text { daño medular }\end{array}$ & 58 & 212 & $\begin{array}{c}\text { Varía } \\
\text { con los } \\
\text { ingresos } \\
\end{array}$ \\
\hline Baldwin & 1985 & Encuesta & 480 & $\begin{array}{l}\text { Niños con } \\
\text { discapacidad } \\
\text { severa }\end{array}$ & - & - & 38 \\
\hline $\begin{array}{l}\text { Instituto } \\
\text { Municipal de } \\
\text { Personas con } \\
\text { Discapacidad y } \\
\text { Ayuntamiento } \\
\text { de Barcelona }\end{array}$ & $2006^{\star}$ & Varios & - & $\begin{array}{l}\text { Personas con } \\
\text { discapacidad } \\
\text { visual, auditiva, } \\
\text { intelectual } \\
\text { y mental de } \\
\text { la ciudad de } \\
\text { Barcelona } \\
\end{array}$ & 166 & 819 & 480 \\
\hline FEAPS & 2009 & Varios & & \begin{tabular}{|l|}
$\begin{array}{l}\text { Discapacidad } \\
\text { intelectual }\end{array}$ \\
\end{tabular} & 209 & 384 & 338 \\
\hline $\begin{array}{l}\text { Mathews y } \\
\text { Truscott (1990) }\end{array}$ & 1990 & $\begin{array}{l}\text { Diarios de } \\
\text { gasto }\end{array}$ & & FES $^{c}$ & - & - & 13 \\
\hline $\begin{array}{l}\text { Jones y } \\
\text { O’Donnell (1995) }\end{array}$ & 1995 & $\begin{array}{l}\text { Escalas de } \\
\text { equivalencia }\end{array}$ & & \begin{tabular}{|l} 
Hogares con \\
personas con \\
discapacidad
\end{tabular} & & & \\
\hline $\begin{array}{l}\text { Instituto de } \\
\text { Políticas } \\
\text { Públicas de } \\
\text { California } \\
\end{array}$ & 2000 & Encuesta & & $\begin{array}{l}\text { Beneficiarios } \\
\text { sociales }\end{array}$ & - & - & 35 \\
\hline $\begin{array}{l}\text { Dobson y } \\
\text { Middleton }\end{array}$ & 1998 & $\begin{array}{l}\text { Presupuesto } \\
\text { estandarizado }\end{array}$ & 300 & $\begin{array}{l}\text { Niños con } \\
\text { discapacidades } \\
\text { severas }\end{array}$ & - & 162 & - \\
\hline $\begin{array}{l}\text { Berthoud, Lakey } \\
\text { y McKay }\end{array}$ & 1993 & Nivel de vida & & $\begin{array}{l}\text { Hogares con } \\
\text { personas con } \\
\text { discapacidad } \\
\end{array}$ & 24 & 109 & - \\
\hline
\end{tabular}




\begin{tabular}{|c|c|c|c|c|c|c|c|}
\hline $\begin{array}{l}\text { Zaidi y } \\
\text { Burchardt }\end{array}$ & 2003 & Nivel de vida & & $\begin{array}{l}\text { Hogares con } \\
\text { personas con } \\
\text { discapacidad }\end{array}$ & 34 & 199 & - \\
\hline NRB $^{d}$ & 1995 & $\begin{array}{l}\text { Encuesta } \\
\text { directa }\end{array}$ & 59 & $\begin{array}{l}\text { Personas con } \\
\text { discapacidad }\end{array}$ & - & 48 & - \\
\hline $\begin{array}{l}\text { Nexus/MS } \\
\text { Irlanda }\end{array}$ & & $\begin{array}{l}\text { Encuesta } \\
\text { directa }\end{array}$ & & $\begin{array}{l}\text { Personas con } \\
\text { esclerosis } \\
\text { múltiple }\end{array}$ & 29 & 39 & - \\
\hline Langa et al. & 2000 & $\begin{array}{l}\text { Horas de } \\
\text { cuidado }\end{array}$ & & $\begin{array}{l}\text { Discapacidad } \\
\text { intelectual }\end{array}$ & - & - & - \\
\hline Smith et al. & 2004 & $\begin{array}{l}\text { Presupuestos } \\
\text { estandarizados }\end{array}$ & 78 & $\begin{array}{l}\text { Discapacidades } \\
\text { varias }\end{array}$ & \multicolumn{3}{|c|}{$\begin{array}{l}\text { Los presupuestos mínimos } \\
\text { van de } 389 £ \text { a } 1.513 £ \text { por } \\
\text { semana }\end{array}$} \\
\hline
\end{tabular}

* Datos también de 2006.

a. OPCS: Office of Population Censuses and Surveys Classification. b. DIG: The Disablement Income Group.

c. FES: Family Expenditure Survey. d. NRB: National Rehabilitation Board.

Fuente: Elaboración propia a partir de los diferentes estudios (Dobson y Middleton, I998; FEAPS, 2009; Hyman, I977; Hughes y Purdy, I999; Large, I99 I; Martin y White, I988; Mathews y Truscott, I990; Thompson et al., I990; Saunders, 2006; Smith et al., 2004; Tibble, 2005; Saunders, 2006; Instituto Municipal Personas con Discapacidad de Barcelona, 2006; Zaidi y Burchard, 2003).

La existencia de diferentes enfoques metodológicos complica la comparación de las distintas investigaciones de forma coherente. Las estimaciones varían ampliamente, aunque en parte esto es debido a que a menudo se tienen en cuenta distintos factores para medirlos (como la composición del hogar, los distintos tipos de deficiencia y niveles de severidad, la edad y el lugar de residencia, entre otros). Por lo tanto, es posible que el desacuerdo que aparentemente existe en la estimación del coste extraordinario no sea tan grande como en principio parece, sino que más bien sea el resultado de la heterogeneidad de los estudios.

En el Cuadro I, se muestra el resumen de lo encontrado en la revisión bibliográfica de los principales estudios realizados sobre la existencia y cuantificación de los costes extraordinarios de la discapacidad. Este cuadro pone de manifiesto la dificultad para comparar de forma directa las estimaciones que éstos ofrecen.

Además, los estudios sobre pobreza y discapacidad muestran que el umbral de la pobreza se sitúa en un nivel más bajo para las personas con discapacidad que para la población general (Zaidi y Burchardt, 2003; Mohapatra, 2004; Kuklys, 2005; Chowdhury, 2005; Palmer et al., 2006; y Parckar 2008). Por otra parte, en los países de menor renta o en los que existe un menor acceso a la oferta de servicios sociales (educación, rehabilitación o tratamientos sanitarios), así como mayores barreras, aparecen altos costes extraordinarios por motivos de discapacidad, que conducen a un mayor grado de pobreza que en países donde el acceso es mayor. Así lo muestran diversos estudios empíricos realizados para establecer el vínculo entre discapacidad y pobreza, los cuales dedican un espacio para tratar los costes extraordinarios de la discapacidad. Estos estudios se han realizado mayormente en países de África (como Malawi, Uganda y Zimbawe) y Asia (como Bangladés, India y Pakistán) [(Dataline, I997; Gooding, 2006; Harris-White, 2003; Helander, I993; Lwanga-Ntale, 2003; Loeb y Eide, 2003 a, 2003b y 2004; y Hoogeveen, 2005). 


\section{La discapacidad en las políticas de desarrollo}

Existe una relación recíproca entre la vulneración de los derechos humanos y la existencia de costes extraordinarios. Por una parte, la vulneración de los derechos de las personas con discapacidad genera costes extraordinarios, que conducen, a su vez, a situaciones de pobreza. Por otra, la existencia de costes extraordinarios no cubiertos genera una pérdida de derechos para las personas con discapacidad, y las coloca en una situación de desventaja y desigualdad.

Si se toman los estudios llevados a cabo sobre la pobreza y sobre los costes extraordinarios de la discapacidad y se comparan con los realizados en países de renta alta y renta baja, se observa claramente que los costes de la discapacidad no se pueden reducir sólo mediante el aumento de los ingresos, sino que es necesario fomentar el desarrollo de políticas dirigidas a eliminar las barreras a las que se enfrentan las personas con discapacidad en su proceso de inclusión en la sociedad, así como a no generar nuevas barreras (Martínez Ríos, 20I I).

La inclusión es la manera más eficaz de reducir los costes de la discapacidad. Una inclusión efectiva requiere que se tenga en cuenta la discapacidad de manera transversal en la legislación, el desarrollo de políticas y la puesta en marcha de programas y acciones desde que se conciben, permitiendo la participación de las personas con discapacidad desde el inicio del proceso. A este fin, las políticas de cooperación para el desarrollo se convierten en una herramienta fundamental, puesto que las personas con discapacidad no se encuentran dentro de la agenda política de muchos países de renta baja, sino que permanecen invisibles y olvidadas.

Sin embargo, el concepto de desarrollo inclusivo no se aplica realmente en la puesta en marcha de las políticas generales de cooperación internacional. En lo que se refiere a las personas con discapacidad, en muchas ocasiones este concepto se ha circunscrito a las acciones de desarrollo centradas en ellas. Es necesario incluir el aspecto de la discapacidad de manera transversal en las políticas de desarrollo, desde un enfoque basado en los derechos humanos, de manera que esté presente en todos los ámbitos de acción, incluidas las políticas generales, para conseguir que la acción sea eficaz (Martínez Ríos, 20I2).

La inclusión social sólo se podrá lograr creando las instituciones necesarias para ello y consiguiendo que éstas trabajen para reducir los costes extraordinarios de la discapacidad. A este respecto, es imprescindible el acceso universal a los derechos fundamentales, como la alimentación, el vestido, el agua y la vivienda, a los servicios apropiados, a la protección social, a la educación y a la sanidad, por citar algunos. Pero también es necesaria su inclusión activa a través del empleo y la participación social y política, reduciendo los costes extraordinarios indirectos y contribuyendo al desarrollo general de la sociedad y la reducción de la pobreza.

La acción debe ser transversal, porque la discapacidad se encuentra presente en cualquier grupo poblacional, en cualquier edad, ámbito geográfico y nivel socioeconómico, entre otras características. Es, por lo tanto, necesario que los servicios básicos existentes sean accesibles para todas las personas, incluidas las personas con discapacidad. Además, los proyectos aislados pueden producir resultados, pero no suelen tener un efecto sostenible y sistémico. Por consiguiente, es preciso un enfoque inclusivo que cambie el sistema e involucre a todos los actores, tanto públicos como privados, y a todos los ámbitos relevantes, de manera horizontal y vertical. Los recursos básicos deben estar disponibles para todas las personas en igualdad de condiciones. Los servicios segregados o separados sólo se pueden justificar en raras ocasiones. Es necesario garantizar el desarrollo de procesos de concienciación y formación sobre discapacidad siguiendo un enfoque basado en los derechos humanos, así como su empoderamiento específico para promover su participación en todas las esferas. 
A tal fin, debe seguirse un proceso dual, tal y como indica el artículo 32 de la Convención sobre los Derechos de las Personas con Discapacidad:

I. Centrarse en la sociedad para eliminar las barreras que producen la exclusión de las personas con discapacidad en todos los ámbitos (transversalización / acción horizontal).

2. Realizar una acción directa sobre la población de personas con discapacidad excluidas con perspectiva de género, para fortalecer y apoyar sus capacidades, de forma que puedan luchar por su inclusión (acción sectorial). Se trata de acciones destinadas a lograr el empoderamiento de las personas, para reducir la brecha de discriminación y desigualdad contra ellas.
El desarrollo a menudo ha introducido nuevos obstáculos en la participación de las personas con discapacidad: edificios nuevos con barreras arquitectónicas; diseños de entornos, bienes y promoción de servicios que no toman en consideración sus características específicas, su situación de mayor vulnerabilidad a la violencia, su menor poder adquisitivo, sus especificidades para acceder a la información, a la comunicación y a las nuevas tecnologías, entre otros factores. El primer paso para conseguir un enfoque más inclusivo es remitirse a los marcos de desarrollo generales e incluir la discapacidad como un elemento de aplicación inmediata, para conseguir la participación activa de las personas con discapacidad. 


\section{Referencias bibliográficas}

Balyies, C. (2002): "Disability and the notion of human development: Questions of rights and capabilities", Disability and Society, I7 (7): 725-739.

Banco Mundial (200I): World Development Report 2000/200I, Washington, D.C.: Oxford University Press.

Berthoud, R. (I993): "Meeting the costs of disability”, en Dalley, G. (ed.), Disability and Social Policy, London: PSI.

Bolderson, H. et al. (2002): Definiciones de la discapacidad en Europa: análisis comparativo, Brunel University.

Brock, K. (I999): Voices of the Poor: 'It's Not Only Wealth that Matters - It's Peace of Mind Too': A Review of Participatory Work on Poverty and Illbeing, Brighton: Institute of Development Studies.

Cejudo, R. (2007): "Capacidades y libertad. Una aproximación a la teoría de Amartya Sen”, Revista Internacional de Sociología, LXV (47): 9-22.

Chowdhury, J. (2005): "Disability and Chronic Poverty: An Empirical Study on Bangladesh” [tesis doctoral], Oxford: Oxford University.

Coleridge, P. (2006): Disability, Liberation and Development, London: Oxfam.

Cornia, G.A. et al. (comp.) (1987): Ajuste con rostro humano, Madrid: Unicef.

Dataline (I997): Study of Existing Services for the Visually Impaired in Pakistan, SSI.

Dobson, B. y Middleton, S. (1998): Paying to Care. The Cost of Childhood Disability, York: Joseph Rowntree Foundation.

Elwan, A. (I999): Poverty and Disability. A Survey of the Literature, serie Social Protection Discussion Paper, n. ${ }^{\circ}$ 9.932, Washington, D.C.: Banco Mundial.

FEAPS (2009): Estudio del sobreesfuerzo económico que la discapacidad intelectual ocasiona en la familia en España, Madrid: Antares Consulting; Endesa.

Freire, P. (1986): La pedagogía de los oprimidos, México D.F.: Siglo XXI.

Fukuda-Parr, S. y Shiva Kumar, A. K. (2003): Readings in Human Development, New Delhi: Oxford University Press.

Gooding, K (2006): Briefing Paper. Poverty and Blindness: A Survey of the Literature, London: Sight Savers International.

Groce, N et al. (20II): Poverty and Disability. A Critical Review of the Literature in Low and Middle-income Countries, serie Working Paper, $\mathrm{n}^{\circ}$ I 6, London: University College of London; Leonard Cheshire Disability.

Harris-White, B. (2003): "Poverty and disability with special reference to rural South Asia" [comunicación en congreso], I International Conference Staying Poor: Chronic Poverty and Development Policy, $7^{\text {th }} 9^{\text {th }}$ April 2003, University of Manchester.

Helander, E. (1993): Prejudice and Dignity: An Introduction to Community-based Rehabilitation, New York: Programa de Naciones Unidas para el Desarrollo.

Hoogeveen, J. (2005): “Measuring welfare for small but vulnerable groups: Poverty and disability in Uganda", Journal of African Economies, I4 (4): 603-63I.

Hughes, D. y Purdy, F (1999): A Survey of the Unavoidable Cost of Disability among 200 People with Quadriplegia, Sydney: The Australian Quadriplegic Association.

Hyman, M. (1977): The Extra Cost of Disabled Living, London: National Fund for Research into the Crippling Diseases.

Indecon (2004): Indecon Report on the Cost of Disability, Dublin: National Disability Authority.

Kuklys, W. (2005): Amartya Sen's Capability Approach: Theoretical Insights and Empirical Applications, New York: Springer. 
Large, P. (I99I): "Paying for the additional costs of disability", Dalley, G. (ed.), Disability and Social Policy, London: Policy Studies Institute.

Lewis, W.A. (1954): "Economic development with unlimited supplies of labour", Manchester School of Economics and Social Studies, XII (2).

Loeb, M.E: y Eide, A.H. (eds.) (2004): Living Conditions of People with Disabilities in Southern Africa - Malawi, Trondheim, SINTEF Health Research.

- (2003a): Living Conditions of People with Disabilities in Southern Africa - Namibia, Trondheim, SINTEF Health Research.

- (eds.) (2003 b): Living Conditions of People with Disabilities in Southern Africa - Zimbawe, Trondheim, SINTEF Health Research.

Lwanga-Ntale, C. (2003): "Chronic poverty and disability in Uganda" [comunicación en congreso], I International Conference Staying Poor: Chronic Poverty and Development Policy, $7^{\text {th }}-9^{\text {th }}$ April 2003, University of Manchester.

Malo, M.A. y Dávila, C. (2006): La protección social de las personas con discapacidad: ayudas técnicas, ayudas personales y pobreza, Madrid, Ministerio de Trabajo y Asuntos Sociales.

Martin, J. y White, A. (1988): OPCS Report 2: The Financial Circumstances of Disabled Adults Living in Private Households, Londres: HMSO.

Martínez Ríos, B. (20I2): La situación de la discapacidad en la política española de cooperación para el desarrollo, Madrid: CERMI.

- (20I I): Discapacidad, pobreza y derechos humanos: aproximación a los costes extraordinarios de la discapacidad y su contribución a la pobreza desde un enfoque basado en los derechos humanos, Madrid: CERMI.

- (2006): "Los costes extraordinarios de la ceguera en la población afiliada a la ONCE de 18 a 65 años de Madrid” [tesina inédita], Madrid: Universidad Complutense de Madrid.

Mathews, A. y Truscott, P. (I990): Disability, Household Income and Expenditure: A Followup Survey of Disabled Adults in the Family
Expenditure Survey, serie DSS Research Report, $\mathrm{n}^{\circ}$ 2, London: HSMO.

Max-Neef, M. (I986): "Human scale economics: The challenges ahead", en Etkins, P., The Living Economy: A New Economics of the Making, London: Routledge.

Metts, R. (2000): Disability Issues, Trends and Recommendations for the World Bank, Washington, D.C.: Banco Mundial.

Mohapatra, C. (2004): "Poverty and disability in India" [comunicación en taller], Disability Management in India: Challenges and Perspectives, $4^{\text {th }}-5^{\text {th }}$ March, New Delhi: Ministry of Social Justice and Empowerment; Indian Institute of Public Administration.

Narayan, D. y Petesch, P. (2002): From Many Lands, serie Voices of the Poor, vol. III, Washington, D.C.: Banco Mundial.

Narayan, D. et al. (2000): Crying Out for Change, serie Voices of the Poor, vol. II, Washington, D.C.: Banco Mundial.

Narayan, D. et al. (I999): Can Anyone Hear Us?, serie Voices of the Poor, vol. I, Washington, D.C.: Banco Mundial.

Nussbaum, M.C. y Sen, A. (1993): The Quality of Life, Oxford: Clarendon Press.

OIT (I976): Declaration of Principles and Programme of Action for a Basic Needs Strategy for Development adopted by the Tripartite World Conference on Employment, Income Distribution and Social Progress, Genève: Organización Internacional del Trabajo.

OMS (20I I): Informe mundial sobre la discapacidad, Genève: Organización Mundial de la Salud.

ONU (2009): The Secretary General. Message on the International Day of Persons with Disabilities. 3 December 2009 (en línea), $<$ http://www.un.org/disabilities/documents/ events/idpdo9_sg_message.pdf>, acceso $20 \mathrm{de}$ febrero de 2013.

- (2006a): Convención Naciones Unidas sobre los Derechos de las Personas con Discapacidad, New York: Organización de las Naciones Unidas. 
- (2006b): In-depth Study on All Forms of Violence against Women [informe del secretario general a la Asamblea General, A/6I/I 22/ Add.r], New York: Organización de las Naciones Unidas.

- (2006c): International Convention on the Rights of Persons with Disabilities. Some Facts about Persons with Disabilities (en línea), <http:// www.un.org/disabilities/convention/pdfs/ factsheet.pdf $>$, acceso 20 de febrero de 2013.

O'Reilly, A. (2003): "Employment barriers for women with disabilities”, en O'Reilly, A., The Right to Decent Work of Persons with Disabilities, serie Skills Working Paper, $\mathrm{n}^{\circ}$ I4, Genève: Organización Internacional del Trabajo.

Palmer, G. et al. (2006): Monitoring Poverty and Social Exclusion 2006, York: Joseph Rowntree Foundation.

Parckar, G. (2008): Disability Poverty in the UK, London: Leonard Cheshire Disability.

PNUD (20I0): Informe sobre desarrollo humano. La verdadera riqueza de las naciones: caminos al desarrollo bumano, New York: Programa de Naciones Unidas para el Desarrollo.

- (2006): Informe sobre desarrollo humano. Más allá de la escasez: poder, pobreza y la crisis mundial del agua, New York: Programa de Naciones Unidas para el Desarrollo.

- (2005): Informe de desarrollo humano mundial, New York: Programa de Naciones Unidas para el Desarrollo, cap. 2.

- (I990): Human Development Report I990, New York: Oxford University Press.

Quinn, G. et al. (2002): Derechos humanos y discapacidad. Uso actual y posibilidades futuras de los instrumentos de derechos humanos de las Naciones Unidas en el contexto de la discapacidad, New York: Organización de las Naciones Unidas.

Robeyns, I. (2005): "The capability approach: A theoretical survey", Journal of Human Development, 6 (I).

Saunders, P. (2006): The Costs of Disability and the Incidence of Poverty, serie Discussion Paper, $\mathrm{n}^{\mathrm{o}}$ I 47, Sydney: Social Policy Research Centre.
Sen, A. (2004): "Discapacidad y justicia” [ponencia], II Conferencia Internacional sobre Discapacidad y Desarrollo Inclusivo: Compartir, Aprender y Construir Alianzas, Washington, D.C.: Banco Mundial.

- (2000): Libertad y desarrollo, Barcelona: Planeta.

- (I988): "Family and food: Sex bias in poverty", en Srinivasan, T.N. y Bardhan, P.K. (eds.), Rural Poverty in South Asia, New York: Columbia University Press, 453-472.

Smith, A. (I79I): The Wealth of Nations, London: Everyman's Library.

Smith, N. et al. (2004): Disabled People's Costs of Living. More than you Would Think, York: University of Loughborough.

Stiglitz, J. (I974): "Incentives and risk sharing in sharecropping”, Review of Economic Studies, 4I: 2I9-255.

Thompson, P. et al. (I990): Short Changed by Disability, London: The Disablement Income Group.

Tibble, M. (2005): Review of Existing Research on the Extra Costs of Disability, serie Working Paper, $n^{\circ}$ 2I, Leeds: Department of Work and Pensions.

Women's Refugee Commission (2009): Disability at a Glance: Refugees with Disabilities (en línea), $<$ http://www.womensrefugeecommission.org/ docs/wrc_disabilities.pdf>, acceso Io de mayo de 20 I2.

Yeo, R (2003): “To what extent are disabled people included in international development work? How can the barriers to inclusion be overcome?" [comunicación en congreso], International Conference Staying Poor: Chronic Poverty and Development Policy, $7^{\text {th }}-9^{\text {th }}$ April 2003, University of Manchester.

Zaidi, A. y Burchard, T. (2003): Comparing Incomes When Needs Differ: Equivalisation for the Extra Costs of Disability in the UK, serie CASE Paper, $\mathrm{n}^{\circ}$ 64. London: Centre for Analysis of Social Exclusion. 